\title{
Serum Soluble Interleukin 6 (IL-6) Receptor and IL-6/Soluble IL-6 Receptor Complex in Systemic Juvenile Rheumatoid Arthritis
}

\author{
Fabrizio De Benedetti, Margherita Massa, Patrizia Pignatti, Salvatore Albani, Daniela Novick, * and Alberto Martini \\ Clinica Pediatrica, Universitá degli Studi di Pavia, Instituto di Ricovero e Cura a Carattere Scientifico Policlinico San Matteo, \\ 27100 Pavia, Italy; and *Department of Molecular Genetics and Virology, Weizmann Institute, 76100 Rehovot, Israel
}

\begin{abstract}
By using a sandwich ELISA, soluble human IL-6 receptor (sIL-6 R) levels were measured in the sera of 20 healthy children and of 25 patients with systemic juvenile rheumatoid arthritis (JRA). In patients with systemic JRA, serum sIL-6 R levels $(114.6 \pm 37.7 \mathrm{ng} / \mathrm{ml})$ were significantly lower $(P<0.01)$ than those of healthy children $(161.2 \pm 45.5 \mathrm{ng} / \mathrm{ml})$. Serum SIL-6 R levels were negatively correlated $(r=-0.610, P$ $<0.001$ ) with serum IL-6 levels measured with the B9 cells. The serum IL-6/sIL-6 R complex was detected using an ELISA based on a monoclonal antibody to IL-6 for capture and on a monoclonal antibody to human sIL-6 $R$ for detection. Healthy controls had little, if any, detectable serum IL-6/sIL$6 \mathrm{R}$ complex (OD $0.024 \pm 0.027$ ), while the majority of patients with systemic JRA presented measurable serum IL-6/sIL-6 R complex (OD 0.492 \pm 0.546 ). IL-6 levels estimated in the circulating IL-6/sIL-6 R complexes were in the range of nanograms per milliliter and $\sim 20$-fold higher than those measured by the B9 cells. Since serum $\mathrm{C}$-reactive protein concentrations were much more correlated with serum levels of IL-6/sIL-6 R complexes $\left(r=0.713, r^{2}=0.51, P<0.0001\right)$ than with the serum IL-6 levels measured with the B9 cells $\left(r=0.435, r^{2}\right.$ $=0.19, P=0.05$ ), the large quantities of serum IL-6 present in IL-6/sIL-6 R complexes appear to be biologically relevant in vivo, at least as far as the induction by IL-6 of acute phase protein production. (J. Clin. Invest. 1994.93:2114-2119.) Key words: interleukin $6 \cdot$ interleukin 6 receptor $\bullet C$-reactive protein - juvenile rheumatoid arthritis
\end{abstract}

\section{Introduction}

IL-6 has multiple biological effects on immune and inflammatory responses (for review see reference 1 ). It has been shown to induce fever and hepatocyte acute phase response, to enhance proliferation and maturation of B cells as well as immunoglobulin production, and to activate $\mathrm{T}$ lymphocyte function. Elevated levels of IL-6 have been found in peripheral blood or other biological fluids in a variety of diseases, including bacterial and viral infections, neoplasia, trauma, and chronic inflammatory diseases (2).

The receptor mediating the biological activities of IL-6 has been identified as two different membrane glycoproteins, an

Address correspondence to Alberto Martini, M.D., Clinica Pediatrica, IRCCS San Matteo, P. le Golgi 2, 27100 Pavia, Italy.

Received for publication 16 September 1993.

J. Clin. Invest.

(C) The American Society for Clinical Investigation, Inc.

$0021-9738 / 94 / 05 / 2114 / 06 \$ 2.00$

Volume 93, May 1994, 2114-2119
$80-\mathrm{kD}$ protein, referred to as the ligand-binding protein (IL-6 receptor [IL-6 R]), ${ }^{1}$ and a $130-\mathrm{kD}$ protein, referred to as the signal transducing protein $(3,4)$. cDNA encoding both molecules has been cloned and expressed and its biochemical properties were analyzed (3-5). In particular, a genetically engineered truncated form of the $80-\mathrm{kD}$ IL-6 R, lacking the transmembrane and the intracytoplasmatic domains, has been expressed successfully and has been shown to be able to associate with the $130-\mathrm{kD}$ protein in the presence of IL-6 and to mediate IL-6 functions (6). Moreover, a soluble form of IL-6 R (sIL-6 R) has been purified as a $50-\mathrm{kD}$ protein from human urine (7) and has been shown to be present in human serum and to bind recombinant human IL-6 with a binding affinity similar to that of the entire recombinant IL-6 R molecule (8).

Juvenile rheumatoid arthritis (JRA) is a clinically heterogenous condition currently divided into different clinical forms based on symptoms at onset (9). The systemic form is characterized by chronic arthritis associated with high spiking fever, other systemic features, including evanescent cutaneous rash, hepatosplenomegaly, lymphoadenomegaly, and serositis, and with prominent laboratory evidence of inflammation (9). The other JRA onset forms are characterized mainly by chronic joint inflammation and are subdivided according to the number of joints involved during the first 6 mo of disease in pauciarticular (four or less joints involved) or polyarticular JRA (five or more joints involved) (9). We have shown previously that serum and synovial fluid IL-6 levels are elevated in patients with JRA during active disease and normalize during remission $(10,11)$. In patients with systemic JRA, serum IL-6 levels are much higher than those present in patients with polyarticular or pauciarticular JRA $(10,11)$ or in patients with adult rheumatoid arthritis $(12,13)$. In addition, in patients with systemic JRA, synovial fluid IL-6 levels are significantly higher than those present in patients with polyarticular or pauciarticular JRA or in patients with adult rheumatoid arthritis (De Benedetti, F., V. Gerloni, M. Massa, P. Pignatti, R. Caporali, C. M. Montecucco, K. Matsushima, F. Fantini, and A. Martini, manuscript in preparation). Moreover, in systemic JRA, serum IL-6 levels are correlated with the extent and severity of joint involvement and with platelet counts (10). Taken together, these data suggest that IL-6 plays an important role in the pathogenesis of systemic JRA. To better understand the biology of IL-6 and its relation to the sIL- 6 R in systemic JRA, in this study we measured serum sIL-6 R levels, evaluated their relation with IL- 6 levels, and developed an assay system for the detection of IL-6/sIL-6 R complexes in sera of patients with systemic JRA.

1. Abbreviations used in this paper: AP, alkaline phosphatase; CRP, C-reactive protein; HGF, hybridoma growth factor; IL-6 R, IL-6 receptor; JRA, juvenile rheumatoid arthritis; sIL-6 R, soluble IL-6 R. 


\section{Methods}

Patients. 60 children (mean age $7.2 \mathrm{yr}$, range 2-17 yr) who fulfilled the American College of Rheumatology's (formerly the American Rheumatism Association) proposed criteria for the diagnosis of JRA (9) were included in the study. 25 had systemic, 15 polyarticular, and 20 pauciarticular JRA. HLA B27 or rheumatoid factor-positive (by Latex agglutination test) patients were excluded from the study. All patients were studied during active disease as defined by the presence of synovitis on examination. Six patients were receiving no treatment. The others were treated with nonsteroidal antiinflammatory drugs, associated in approximately half of them with methotrexate (single weekly dose) and /or prednisone (on an alternate-day regimen in the majority of cases). During the course of this study, some patients were tested more than once during different phases of the disease or during different treatments. Sera obtained from 20 healthy children (mean age 8.1 $\mathrm{yr}$, range 3-18 yr), hospitalized for bone marrow donation or for minor surgical procedures, were used as controls. Permission for drawing of extra blood during routine venipuncture was obtained from parents of all children.

Blood was allowed to clot for $2 \mathrm{~h}$ at room temperature and centrifuged at $1,500 \mathrm{~g}$ for $10 \mathrm{~min}$. Sera were stored at $-70^{\circ} \mathrm{C}$ until used. 12 synovial fluid samples, 3 from patients with systemic JRA and 9 from patients with pauciarticular JRA, obtained before intraarticular steroid injection were also studied. Synovial fluids were centrifuged at $10,000 \mathrm{~g}$ for $10 \mathrm{~min}$ and stored at $-70^{\circ} \mathrm{C}$ until use.

Assay procedure for $S I L-6 R$. sIL-6 R levels were measured using a sandwich ELISA, based on the use of monoclonal antibodies 34.14 and alkaline phosphatase (AP)-conjugated 22.3. These two monoclonal antibodies were selected for the ELISA because previous studies showed that they bind to different epitopes on the sIL-6 R molecule (14). Polystyrene plates (Costar Corp., Cambridge, MA) were coated overnight at $4^{\circ} \mathrm{C}$ with monoclonal antibody $34.14(20 \mu \mathrm{g} / \mathrm{ml}$ in PBS), and nonspecific binding sites were blocked by further incubation with $\mathrm{PBS} / 2 \% \mathrm{BSA}$ for $1 \mathrm{~h}$ at $37^{\circ} \mathrm{C}$. Serum and synovial fluid samples were added at a 1:100 dilution in PBS/1\% BSA, and the plates were incubated for $3 \mathrm{~h}$ at $37^{\circ} \mathrm{C}$. Natural sIL-6 R, purified to homogeneity from human urine as described previously (15), was used as a standard. After washing, plates were incubated for $2 \mathrm{~h}$ at room temperature with AP-conjugated monoclonal antibody $22.3(0.5 \mu \mathrm{g} / \mathrm{ml}$ in PBS/1\% BSA). The substrate $p$-nitrophenyl phosphate was added, and the optical density read at $405 \mathrm{nM}$. The detection limit of the ELISA is 40 $\mathrm{pg} / \mathrm{ml}$ of purified human sIL-6 $\mathrm{R}$.

Detection of IL-6/sIL-6 R complex. To detect the presence of IL-6/ sIL-6 R complex, we constructed an ELISA based on the use of a monoclonal antibody to human IL-6 (34.1) (kindly provided by Interpharm Laboratories, Nes-Ziona, Israel ) (16) for capture and a monoclonal antibody to the sIL-6 R (AP-conjugated 22.3) for detection. Monoclonal antibody 22.3 was chosen because it was shown not to inhibit the binding of radiolabeled human recombinant IL- 6 to human natural sIL-6 R (14). Polystyrene plates were coated overnight at room temperature with monoclonal antibody 34.1 to IL-6 at a concentration of $50 \mu \mathrm{g} / \mathrm{ml}$ in PBS or with PBS alone. After blocking the nonspecific binding sites with a $2-\mathrm{h}$ incubation at $37^{\circ} \mathrm{C}$ with $\mathrm{PBS} / 2 \% \mathrm{BSA}$, each test serum, diluted 1:1 in PBS, was added to wells coated with monoclonal antibody 34.1 to IL-6 and to wells coated with PBS alone, and the plates were incubated for $2 \mathrm{~h}$ at $37^{\circ} \mathrm{C}$. Plates were not washed, and the AP-conjugated monoclonal antibody 22.3 to the sIL- $6 \mathrm{R}$ was added to the wells containing test samples at a final concentration of $1.3 \mu \mathrm{g} / \mathrm{ml}$. The plates were incubated for $1 \mathrm{~h}$ at $37^{\circ} \mathrm{C}$ with gentle swirling. This approach was chosen because preliminary experiments with patients' sera and with normal sera in the presence of exogenous IL-6 showed that washing the plates followed by a 1-h incubation with AP-conjugated 22.3 in PBS/1\% BSA resulted in a marked decrease in the optical density, conceivably because of dissociation of the IL-6/sIL-6 R complex. After washing the plates, the assay was developed as described for the sIL-6 R ELISA. The background optical density using PBS/2\% BSA as a test sample was always below 0.190 . The results are expressed as specific optical density obtained by subtracting the nonspecific optical density found in wells coated with PBS alone to the optical density observed in wells coated with the monoclonal antibody 34.1 to human IL-6. To compare the levels of IL-6 present in the IL-6/sIL-6 R complex with the amount of IL-6 measured by the hybridoma growth factor (HGF) assay (see below), the amount of IL-6 was extrapolated from a standard curve obtained by adding increasing concentrations of human recombinant IL-6 derived from Chinese hamster ovary cells (Genzyme Corp., Cambridge, MA) to a reference serum from a healthy adult control. This serum had $100 \mathrm{ng} / \mathrm{ml}$ of sIL- $6 \mathrm{R}$ and contained neither detectable IL-6 in the HGF assay nor detectable IL-6/sIL-6 R complex (specific $O D 0.000$ ). To obtain acceptable resolution over a wide range of IL-6 concentrations, optical density at $405 \mathrm{nM}$ was read after different times of incubation with the substrate $p$-nitrophenyl phosphate (see Results and Fig. 5).

Assay for IL-6. IL-6 levels were measured using the hybridoma cell line B9 (kindly provided by Dr. L. Aarden, Netherland Red Cross, Amsterdam), as described previously (10). Chinese hamster ovary cell-derived recombinant human IL-6 (Genzyme Corp.) was used to culture B9 cells and as a standard in the assay. $4 \mathrm{~L}-6$ levels were expressed, unless otherwise indicated, in HGF units (HGF U), where 1 HGF U is the amount of IL- 6 required to achieve half-maximal proliferation of B9 cells. The conversion from HGF $U / \mathrm{ml}$ to $\mathrm{pg} / \mathrm{ml}$ was performed using the amount of human recombinant IL- 6 required to achieve half-maximal proliferation of B9 cells in each assay, that is, $\sim 4.5 \mathrm{pg} / \mathrm{ml}$ of human recombinant IL-6.

Statistical analysis. Data were analyzed using the Mann-Whitney $\mathrm{U}$ test for unpaired samples and the Spearman correlation coefficient.

\section{Results}

sIL-6 R levels in patients with JRA. Patients with systemic JRA presented serum sIL-6 $R$ levels $(114.6 \pm 37.7 \mathrm{ng} / \mathrm{ml})$ significantly lower $(P<0.01)$ than those found in healthy children $(161.2 \pm 45.5 \mathrm{ng} / \mathrm{ml})$, while patients with polyarticular or pauciarticular JRA had serum IL-6 $R$ levels $(176.7 \pm 66.9$ and $165.9 \pm 51.5 \mathrm{ng} / \mathrm{ml}$, respectively) comparable with those of healthy children (Fig. 1). To rule out the possibility that the low serum sIL-6 R levels in patients with systemic JRA could be due to the binding of endogenous IL-6 present in patients' sera to the sIL-6 R, thus masking the epitope recognized by the monoclonal antibodies used in the ELISA, we tested the effect of preincubation of normal sera with exogenous IL-6. As

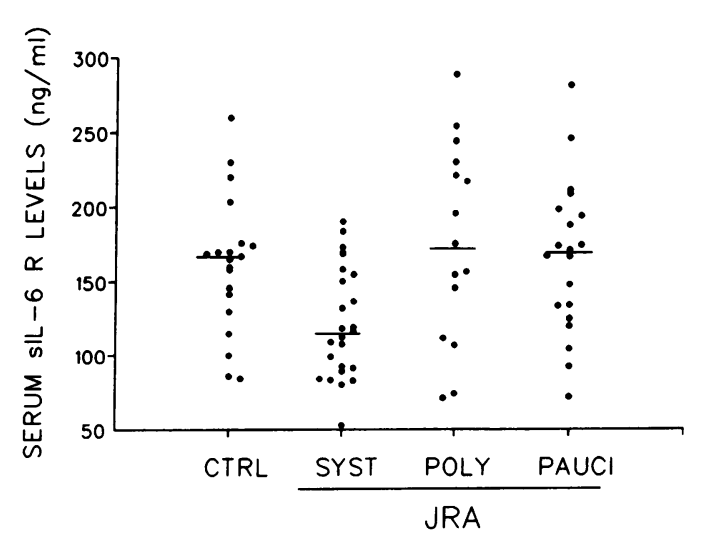

Figure 1. Serum sIL-6 $\mathrm{R}$ levels in healthy controls (CTRL) and in patients with systemic (SYST), polyarticular (POLY), or pauciarticular (PAUCI) JRA. The horizontal continuous line represents the mean of each group. 
shown in Fig. 2 for two representative sera, the addition of 20 $\mathrm{ng} / \mathrm{ml}$ of human recombinant IL-6 did not have an effect on the measurement of the sIL-6 R in the assay system.

When patients with JRA were divided according to their treatment, no differences in serum sIL-6 R levels were observed (data not shown), thus suggesting that nonsteroidal antiinflammatory drugs, prednisone or methotrexate, do not have a direct effect on the release of sIL-6 $R$ in vivo. No significant correlation of serum sIL-6 R levels with erythrocyte sedimentation rate values or with $\mathrm{C}$-reactive protein (CRP) concentrations was found in the three JRA onset types (data not shown).

In patients with systemic JRA, serum sIL-6 $R$ levels were negatively correlated $(r=-0.610, P<0.001)$ with serum IL-6 levels measured with the B9 cells (Fig. 3). To further evaluate the relationship between serum IL- 6 and sIL- 6 R levels, we measured IL-6 and sIL-6 R levels in serum samples obtained during the febrile peak from two patients with systemic JRA. As shown in Fig. 4 for one representative patient, the increase in serum IL-6 levels was associated with a decrease in SIL-6 R, whose levels were inversely related to body temperature.

sIL-6 $\mathrm{R}$ was also found in synovial fluid samples at nanogram per milliliter concentrations with no evident difference among patients with systemic or pauciarticular JRA. As reported previously $(10,11)$, while IL-6 levels were much higher in synovial fluids than in the corresponding serum, this was not true for sIL-6 R, suggesting that, unlike IL-6, sIL-6 R is not preferentially produced at, and thus released from, sites of inflammation (Table I).

Presence of circulating $I L-6 / s I L-6 R$ complex in patients with systemic JRA. To identify the circulating IL-6/sIL-6 R complex, we constructed an ELISA based on the use of a monoclonal antibody to human IL-6 (34.1) for capture and a monoclonal antibody to the sIL-6 R (AP-conjugated 22.3) for detection of the IL-6/sIL-6 R complex. To control for possible nonspecific reactivity secondary to the binding of the serum sIL-6 $R$ to plastic, all sera tested were incubated in wells coated with PBS alone and in wells coated with the monoclonal antibody 34.1 to IL-6. A low background was found with no significant differences in the background optical density obtained in wells coated with PBS alone between sera from patients with systemic JRA $(n=25)$ and sera from healthy controls $(n=12)$ $(0.030 \pm 0.031$ and $0.021 \pm 0.020$, respectively; $P=0.79)$. The

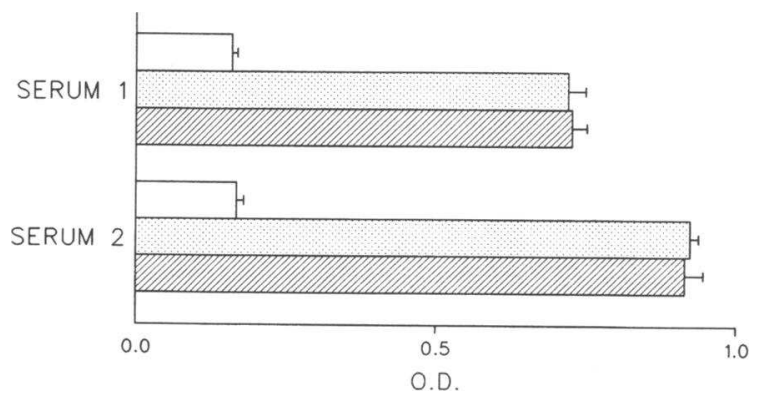

Figure 2. Effect of preincubation of normal sera with recombinant human IL-6 $(20 \mathrm{ng} / \mathrm{ml})$ on the detection of sIL-6 R. Normal sera were incubated at $37^{\circ} \mathrm{C}$ for $45 \mathrm{~min}$ in the absence or in the presence of $20 \mathrm{ng} / \mathrm{ml}$ of recombinant human IL-6 and then tested in the ELISA for sIL-6 R as described in Methods. Results from two representative sera are shown. Background, white box; no IL-6, dotted box; IL-6 (20 $\mathrm{ng} / \mathrm{ml}$ ), striped box.

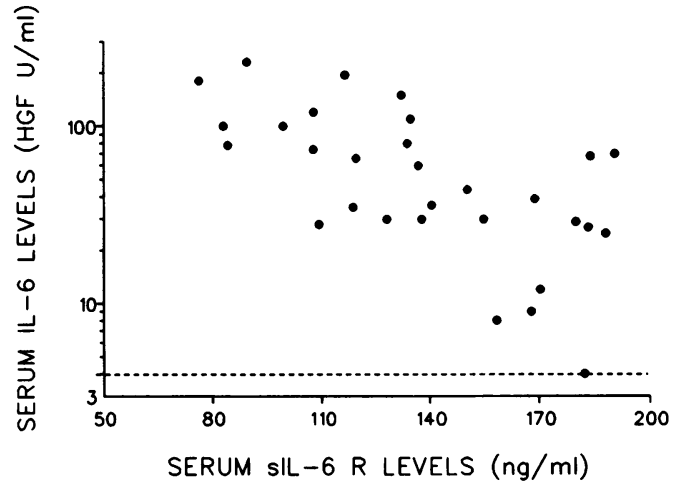

Figure 3. Relationship between serum IL-6 and serum sIL-6 R levels in patients with systemic JRA. Serum IL-6 levels were measured using an HGF assay as described in Methods. The dotted line represents the detection limit of the HGF assay. $r=-0.618 ; P<0.001$.

addition of increasing concentrations of human recombinant IL-6 to normal sera resulted in a dose-dependent increase in specific optical density, demonstrating that this assay system is able to detect the IL-6/sIL-6 R complex formed by the binding of exogenous IL-6 to its soluble receptor in human serum. Dose-response curves obtained at different times of incubation with the substrate for the reference serum are shown in Fig. 5.

As shown in Fig. 6, healthy children had little if any detectable IL-6/sIL-6 $\mathbf{R}$ complex in their serum (specific OD $0.024 \pm 0.027$ ), while the majority of sera from patients with systemic JRA had detectable levels of IL-6/sIL-6 R complex (specific OD $0.492 \pm 0.546$ ) with a highly significant difference with sera from healthy controls $(P<0.0001)$. Comparison of IL-6 levels measured by the HGF assay and those estimated in the IL-6/sIL-6 R complex, as measured by the ELISA, in the same 24 serum samples, lead us to unexpected results. As shown in Table II, in patients with systemic JRA, serum IL-6 levels estimated in the IL-6/sIL-6 R complex were in the range of nanograms per milliliter and were much higher than those measured by the HGF assay (mean ratio IL-6 in IL-6/sIL-6 R complex/IL-6 measured by the HGF assay: 22.4). Of interest, when the same comparison was made for IL- 6 levels present in synovial fluid samples, such a difference was not observed ( Table II). Moreover, comparison of the correlation between IL-6 levels estimated by the two assay systems in sera or in synovial fluids showed that results by the two assay systems are strictly correlated in synovial fluid samples $\left(r^{2}=0.78\right)$ but are much

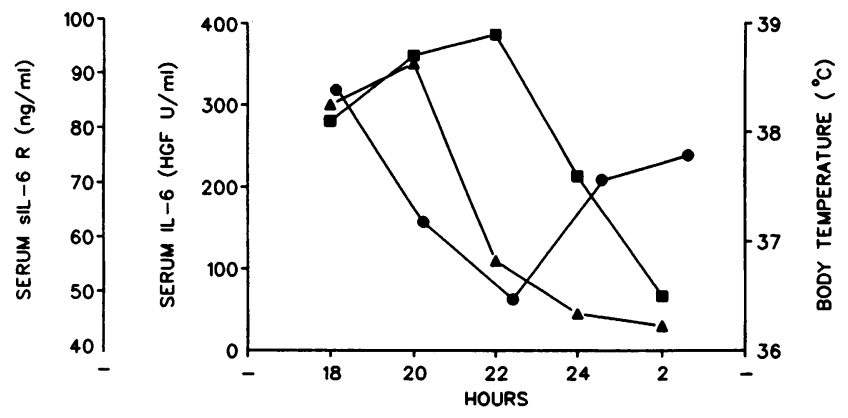

Figure 4. Serum IL-6 and sIL-6 R levels during the febrile peak in representative patients with systemic JRA. Body temperature, closed squares; serum IL-6, closed triangles; serum IL-6 R, closed circles. 
Table I. IL-6 and sIL-6 R Levels in Synovial Fluid and in the Corresponding Serum Samples of Representative Patients with Systemic or Pauciarticular JRA

\begin{tabular}{lrrrrr}
\hline & \multicolumn{2}{c}{ sIL-6 R } & & \multicolumn{2}{c}{ IL-6 } \\
\cline { 2 - 3 } \cline { 5 - 6 } & $\begin{array}{l}\text { Synovial } \\
\text { fluid }\end{array}$ & Serum & & $\begin{array}{c}\text { Synovial } \\
\text { fluid }\end{array}$ & Serum \\
\hline & & $n g / m l$ & & & HGF $U / m l$ \\
Systemic & & & & & \\
1 & 64.8 & 99.4 & & 18500 & 100 \\
2 & 142.6 & 148.9 & 13000 & 39 \\
3 & 138.3 & 168.9 & 5600 & 19 \\
Pauciarticular & & & & \\
1 & 175.6 & 185.1 & 5800 & 18 \\
2 & 80.2 & 148.1 & 6200 & $<4$ \\
3 & 126.7 & 167.1 & 7600 & $<4$ \\
4 & 60.0 & 134.9 & 600 & $<4$ \\
& & & &
\end{tabular}

less correlated in serum $\left(r^{2}=0.44\right)$ (Fig. 7). Taken together, the data in Table II and Fig. 7 suggest that quantities of IL-6 present in serum are much higher than those estimated by the HGF assay and that the factor(s) interfering with the detection of IL- 6 by the HGF assay is present in serum, but not in synovial fluid.

To evaluate the in vivo biological relevance of the large quantities of IL-6 estimated in circulating IL-6/sIL-6 R complexes, we compared the correlation between serum CRP concentrations and the levels of the IL-6/sIL-6 R complex with the correlation between serum CRP concentrations and serum IL6 levels measured with the HGF assay. As shown in Fig. 8, CRP concentrations were much more correlated with the levels of the circulating IL-6/sIL-6 R complex ( $n=24, r=0.713, r^{2}$ $=0.51, P<0.0001)$ than with the serum IL-6 levels measured with the HGF assay $\left(n=24, r=0.435, r^{2}=0.19, P=0.05\right)$.

\section{Discussion}

In this study we have measured serum sIL-6 $\mathrm{R}$ levels in patients with JRA and developed an ELISA for the detection of the

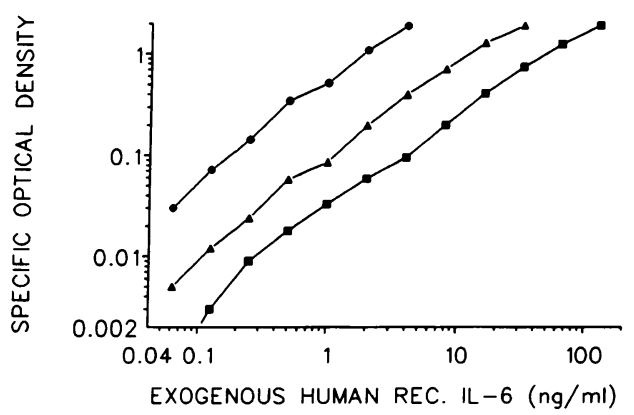

Figure 5. Dose-response curves of the ELISA for the IL-6/sIL-6 R complex. Results from one representative serum from a healthy adult control are shown. The test sample was incubated at $37^{\circ} \mathrm{C}$ for 45 min in the absence or in the presence of increasing concentrations of human recombinant IL- 6 (range $0.062-128 \mathrm{ng} / \mathrm{ml}$ ) and then tested in the ELISA for the IL-6/sIL-6 R complex as described in Methods. The optical density at $405 \mathrm{nM}$ was read after a 30-min (closed square), a 1-h (closed triangles), and a 4-h (closed circles) incubation with the substrate $p$-nitrophenyl phosphate.

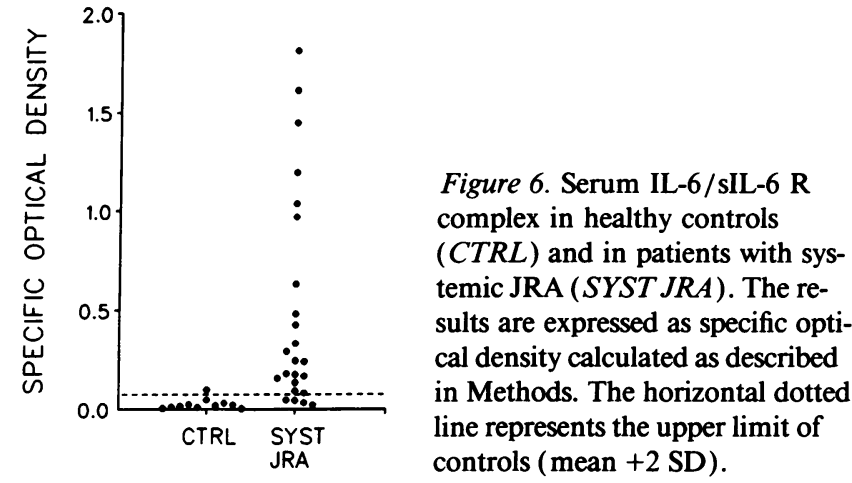

IL-6/sIL-6 R complex in biological fluids, demonstrating that a high amount of IL- 6 circulates as an IL-6/sIL-6 R complex.

The serum sIL-6 $\mathrm{R}$ levels found in our age-matched controls are approximately twofold higher than those reported recently by Honda et al. (8) and by Gaillard et al. (17) in healthy adults. These differences could be because of differences in the antibodies used or possibly differences in the age of the population tested. Indeed, we found that serum sIL-6 R was higher in our age-matched control population (mean level $161.2 \mathrm{ng} / \mathrm{ml}$ ) than in a group of healthy adults $(n=10$; mean level 104.5 $\mathrm{ng} / \mathrm{ml}$ ).

In our study, among patients with JRA, only those with systemic JRA were found to have serum sIL-6 R levels significantly lower than those of healthy controls comparable with age. As far as we know, only two studies are available on serum sIL-6 R levels in human diseases. Patients with HIV infection and patients with multiple myeloma have been reported to have serum sIL-6 $\mathrm{R}$ levels significantly higher than healthy controls $(8,17)$. These data suggest that different modulation of the in vivo levels of sIL-6 R occurs in different disease conditions. This may possibly be because of quantitative differences in IL-6 production in vivo. Indeed, serum IL-6 levels found in patients with HIV infection or with multiple myeloma (18-20) are much lower than those present in patients with systemic JRA (10). A possible role of the increased production of IL-6 in downregulating the levels of sIL-6 $R$ in patients with systemic JRA is suggested by the finding of a negative correlation

Table II. Comparison of the Levels of IL-6 Measured by the HGF Assay and Those Estimated in the Circulating IL-6/sIL-6 $R$ Complex in Sera from Patients with Systemic JRA and in Synovial Fluids from Patients with Systemic or Pauciarticular JRA

\begin{tabular}{lcc}
\hline & HGF assay & IL-6/sIL-6 R ELISA \\
\hline & $n g / m l$ & $n g / m l$ \\
Serum & & \\
$(n=24)$ & $0.335 \pm 0.334$ & $6.850 \pm 8.971$ \\
& $(0.022-1.44)$ & $(0.26-32.0)$ \\
Synovial fluid & & \\
$(n=12)$ & $45.2 \pm 43.2$ & $39.8 \pm 35.4$ \\
& $(1.4-150.0)$ & $(1.6-118.0)$
\end{tabular}

24 sera from patients with systemic JRA and 12 synovial fluid samples, 3 from patients with systemic and 9 from patients with pauciarticular JRA, were tested in both assay systems. Results are shown as means $\pm \mathrm{SD}$. Ranges are shown in parentheses. 

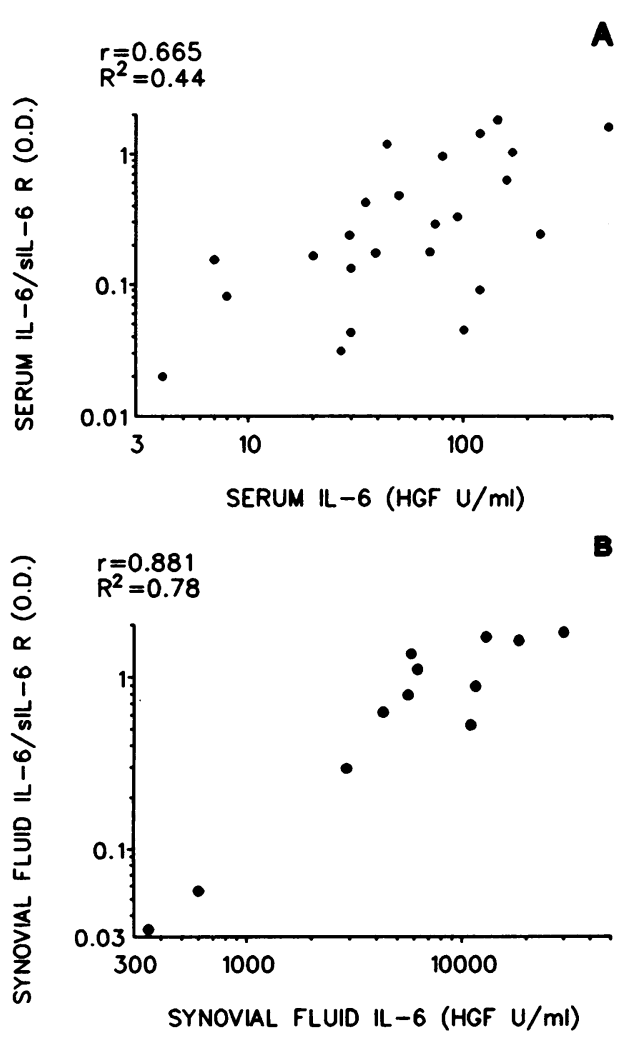

Figure 7. Comparison of the correlation between IL-6 levels measured by the HGF assay with the levels of IL-6/sIL-6 R complex in serum $(A)$ and in synovial fluid $(B)$.

between serum sIL-6 R levels with serum IL-6 levels, measured with the HGF assay, and by the decrease in serum sIL-6 $R$ levels that was associated with the increase in serum IL-6 levels during the febrile peak. The mechanisms of the production of sIL-6 R have not yet been clarified $(21,22)$. Nevertheless, our data suggest that two possible mechanisms, not necessarily mutually exclusive, may account for the decrease in the serum sIL-6 R levels in patients with systemic JRA: $(a)$ since IL-6 has been reported to inhibit the expression of the IL- 6 R gene both in vivo and in vitro (23), a direct effect of increased in vivo IL-6 production on the expression of the IL- 6 R gene is conceivable; and $(b)$ the decrease in serum sIL-6 $R$ levels may be a consequence of a consumption of circulating sIL-6 $R$ due to the formation of IL-6/sIL-6 R complexes in the presence of IL-6 and of the subsequent binding and internalization of the complex by target cells expressing the $130-\mathrm{kD}$ signal transducing protein.

This second hypothesis is based on the assumption that circulating IL-6/sIL-6 R complexes are present in patients with systemic JRA. Since the serum soluble form of IL-6 R and the genetically engineered truncated form of IL- 6 R have been shown to bind IL- 6 with a binding affinity similar to the entire $80-\mathrm{kD}$ molecule $(6,8)$ and given the serum concentrations of the sIL-6 R found in this study, it is conceivable to hypothesize that IL-6 circulates bound to its soluble receptor. To verify this hypothesis, we constructed an ELISA based on the use of a monoclonal antibody to IL-6 for capture and a monoclonal antibody to sIL-6 $\mathrm{R}$ for revealing the presence of the IL-6/sIL$6 \mathrm{R}$ complex. Using this approach we found no evidence of circulating IL-6/sIL-6 R complex in healthy controls. How- ever, preincubation of control sera with increasing concentrations of exogenous human recombinant IL-6 resulted in a dose-dependent increase in optical density, demonstrating that this assay system is able to detect the IL-6/sIL-6 R complex formed by the binding of IL- 6 to its soluble receptor present in human serum. This also confirms the findings of Honda et al. (8) and of Gaillard et al. (17) that circulating soluble IL-6 R is able to bind IL-6. Almost all sera of patients with systemic JRA displayed high optical density in this assay system, demonstrating the presence of elevated serum IL-6/sIL-6 R complex levels. These results suggest strongly that IL-6, or at least part of it, circulates bound to its soluble receptor in patients with systemic JRA. To the best of our knowledge, this is the first demonstration of the presence of circulating cytokine/soluble cytokine receptor complexes in human diseases. Our data are consistent with the following hypothesis on the biology of IL-6: IL-6 produced at sites of inflammation (e.g., joints) or produced in the peripheral blood in response to stimuli released by inflammatory sites (e.g., IL-1 or TNF- $\alpha$ ) binds the serum sIL-6 $R$ and it is vehiculated in the blood as an IL-6/sIL-6 R complex. This binding may protect IL- 6 from protease degradation, in a manner similar to what has been described for IL-4 and the soluble IL-4 receptor (24), and/or stabilize IL-6 bioactivity, as has been demonstrated for TNF- $\alpha$ and its soluble receptors (25). The IL-6/sIL-6 R complex will thus associate with the $130-\mathrm{kD}$ signal transducing protein on the surface of target cells and mediate IL- 6 bioactivities.

Comparison of serum IL- 6 levels measured by the HGF assay and those estimated in circulating IL-6/sIL-6 R com-

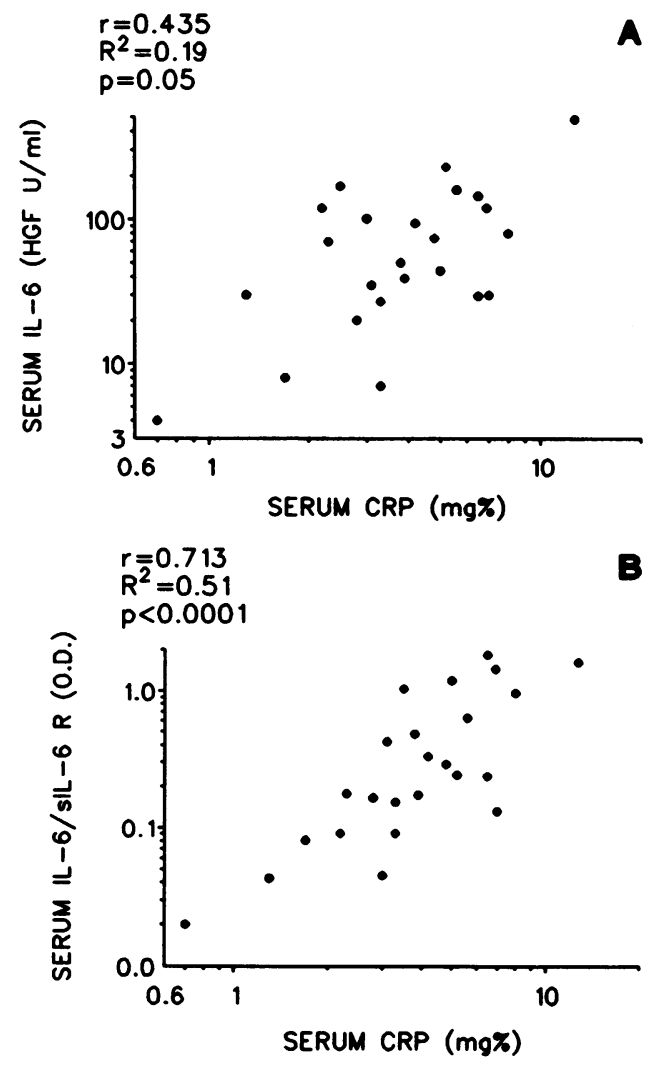

Figure 8. Correlation of serum CRP concentrations with serum IL-6 levels measured by the HGF assay $(A)$ or with circulating IL-6/sIL-6 $\mathrm{R}$ complex levels $(B)$ in patients with systemic JRA. 
plexes led us to the unexpected finding that, in patients with systemic JRA, IL-6 was present in nanogram per milliliter amounts in the circulating IL-6/sIL-6 R complexes compared with the few hundreds of picograms per milliliter measured by the HGF assay. Therefore, our data suggest that in systemic JRA, but also possibly in other disease conditions, IL-6 circulates in much higher amounts than those measured by the HGF assay. The possibility that the HGF assay detects only a portion of IL-6 present in human serum is also supported by the consistent finding that IL-6 levels measured with the hepatocyte-stimulating factor assay have been found to be much higher than those measured by the HGF assay in a variety of disease states (26-29). More recently, May et al. (30) have demonstrated that the bulk of IL-6 present in peripheral blood circulates in two high molecular weight complexes (100-150 and $400-500 \mathrm{kD}$ ) and that this IL-6 is not detected by the HGF assay (30). Of note, among the proteins present in the 100150-kD complex, a 50-kD material was present, consistent with the molecular weight of the human natural sIL-6 R. Taken together, the discrepancies between serum IL-6 levels measured by the HGF assay and by the hepatocyte-stimulating factor assay (26-29), our results, and those of May et al. (30) raise the issue of the biological role of the large quantities of IL- 6 present in the peripheral blood. In our study, the strict correlation of serum IL-6 levels measured in the IL-6/sIL-6 R complex ELISA with CRP concentrations in patients with systemic JRA suggests that the high amounts of IL- 6 present in the circulating IL-6/sIL-6 R complex are biologically relevant in vivo, at least as far as the induction by IL-6 of acute phase protein production.

In conclusion, in this study we reported a decrease in sIL-6 $R$ levels in patients with systemic JRA, a disease characterized by a marked increase in serum IL-6 levels. We developed an assay system for detection and measurement of circulating IL6/sIL-6 R complexes and demonstrated that IL-6 circulates as an IL-6/sIL-6 R complex. We have also found that large quantities of IL-6, not detected by the HGF assay, are present in the peripheral blood of patients with systemic JRA as IL-6/sIL-6 R complexes, whose in vivo biological relevance is suggested by their strict correlation with serum CRP concentrations.

\section{Acknowledgments}

This work was supported by the Istituto di Ricovero e Cura a Carattere Scientifico Policlinico San Matteo, Pavia, Italy and by the Istituto di Ricerca Cesare Serono, Ardea, Italy.

\section{References}

1. Van Snick, J. 1990. Interleukin 6: an overview. Annu. Rev. Immunol. 8:253-278.

2. Hirano, T., S. Akira, T. Taga, and T. Kishimoto. 1990. Biological and clinical aspects of interleukin 6. Immunol. Today. 11:443-449.

3. Yamasaki, T., T. Taga, Y. Hirata, H. Yawata, Y. Kawanishi, B. Seed, T. Taniguchi, T. Hirano, and T. Kishimoto. 1988. Cloning and expression of the human interleukin-6 (BSF-2/IFN $\beta 2$ ) receptor. Science (Wash. DC). 241:825828.

4. Taga, T., M. Hibi, T. Hirata, K. Yamasaki, K. Yasukawa, T. Matsuda, T. Hirano, and T. Kishimoto. 1989. Interleukin 6 triggers the association of its receptor with a possible signal transducer, gp 130. Cell. 58:573-579.

5. Yawata, H., K. Yasukawa, S. Natsuka, M. Murakami, K. Yamasaki, M Hibi, T. Taga, and T. Kishimoto. 1993. Structure-function analysis of the human IL-6 receptor: dissociation of amino acid residues required for IL-6 binding and for IL-6 signal transduction through gp130. EMBO (Eur. Mol. Biol. Organ.) J. 12:1705-1712.

6. Yasukawa, K., T. Saito, T. Fukunaga, Y. Sekimori, Y. Kishihara, H. Fukui, Y. Osugi, T. Matsuda, H. Yawata, T. Hirano, et al. 1990. Purification and charac terization of soluble human IL-6 receptor expressed in CHO cell. J. Biochem. 108:673-681.
7. Novick, D., H. Engelmann, D. Wallach, and M. Rubinstein. 1989. Soluble cytokine receptors are present in normal human urine. J. Exp. Med. 170:14091414.

8. Honda, M., S. Yamammoto, M. Cheng, K. Yasukawa, H. Suzuki, T. Saito, Y. Osugi, T. Tokunaga, and T. Kishimoto. 1992. Human soluble IL-6 receptor its detection and enhanced release by HIV infection. J. Immunol. 148:2175 2180.

9. Brewer, E. J., Jr., J. Bass, J. Baum, J. T. Cassidy, C. Fink, J. Jacobs, V. Hanson, J. E. Levinson, J. Shaller, and J. S. Stillman. 1977. Current proposed revision of JRA criteria. Arthritis Rheum. 20(Suppl.):195-199.

10. De Benedetti, F., M. Massa, P. Robbioni, A. Ravelli, G. R. Burgio, and A Martini. 1991. Correlation of serum interleukin 6 levels with joint involvement and thrombocytosis in systemic juvenile rheumatoid arthritis. Arthritis Rheum. 34:1158-1163.

11. De Benedetti, F., P. Robbioni, M. Massa, S. Viola, S. Albani, and A. Martini. 1992. Serum interleukin 6 and joint involvement in polyarticular and pauciarticular juvenile chronic arthritis. Clin. Exp. Rheumatol. 10:493-498.

12. Hirano, T., T. Matsuda, M. Turner, N. Miyasaka, G. Buchan, B. Tang, K. Sato, M. Shimizu, R. Maini, M. Feldmann, and T. Kishimoto. 1988. Excessive production of interleukin 6/B cell stimulatory factor-2 in rheumatoid arthritis. Eur. J. Immunol. 18:1797-1801.

13. Houssiau, F. A., J. P. Devogelaer, J. Van Damme, C. Nagant de Deuxchaisnes, and J. Van Snick. 1988. Interleukin 6 in synovial fluid and serum of patients with rheumatoid arthritis and other inflammatory arthritis. Arthritis Rheum. 31:784-788.

14. Novick, D., H. Engelmann, D. Wallach, M. Revel, O. Leitner, and M. Rubinstein. 1991. Monoclonal antibodies to the soluble human IL-6 receptor: affinity purification, ELISA, and inhibition of ligand binding. Hybridoma. 10:137-145.

15. Novick, D., H. Engelmann, D. Wallach, O. Leitner, M. Revel, and M. Rubinstein. 1990. Purification of soluble cytokine receptors from normal human urine by ligand-affinity and immunoaffinity chromatography. J. Chromatogr. 510:331-337.

16. Novick, D., Z. Eshhar, M. Revel, and Y. Mory. 1989. Monoclonal antibodies for affinity purification of IL-6/IFN- $\beta 2$ and for neutralization of HGF activity. Hybridoma. 8:561-567.

17. Gaillard, J. P., R. Bataille, H. Brailly, C. Zuber, K. Yasukawa, M. Attal, N Maruo, T. Taga, T. Kishimoto, and B. Klein. 1993. Increased and highly stable levels of functional interleukin 6 receptor in sera of patients with monoclonal gammopathy. Eur. J. Immunol. 23:820-824.

18. Honda, M., K. Kitamura, Y. Mizutani, M. Oishi, M. Arai, T. Okura, K. Igarahi, K. Yasukawa, T. Hirano, T. Kishimoto, et al. 1990. Quantitative analysis of serum IL-6 and its correlation with increased levels of serum IL-2R in HIV-induced diseases. J. Immunol. 145:4059-4064.

19. Bataille, R., M. Jourdan, X.-G. Zhang, and B. Klein. 1989. Serum levels of interleukin 6, a potent myeloma cell growth factor, as a reflect of disease severity in plasma cell dyscrasias. J. Clin. Inv. 84:2008-2011.

20. Ludwig, H., D. Nachbaur, E. Fritz, M. Krainer, and H. Huber. 1991. Interleukin 6 is a prognostic factor in multiple myeloma. Blood. 77:2794-2795.

21. Lust, J. A., K. A. Donovan, M. P. Kline, R. R. Greipp, R. A. Kyle, and N. J. Maihle. 1992. Isolation of an mRNA encoding a soluble form of the human interleukin-6 receptor. Cytokine. 4:96-100.

22. Mullberg, J., H. Schooltink, T. Stoyan, M. Gunther, L. Graeve, G. Buse, A. Mackiewicz, P. C. Heinrich, and S. Rose-John. 1993. The soluble interleukin 6 receptor is generated by shedding. Eur. J. Immunol. 23:473-480.

23. Portier, M., D. Lees, E. Caron, M. Jourdan, J. M. Boiron, R. Bataille, and B. Klein. 1992. Up-regulation of interleukin (IL)-6 receptor gene expression in vitro and in vivo in IL-6 deprived myeloma cells. FEBS (Fed. Eur. Biochem. Soc.) Lett. 302:35-38.

24. Fernandez-Botran, R., and E. S. Vitetta. 1991. Evidence that natural murine soluble interleukin 4 receptors may act as transport proteins. J. Exp. Med. 174:673-681.

25. Aderka, D., H. Engelmann, Y. Maor, C. Brakebusch, and D. Wallach. 1992. Stabilization of the bioactivity of tumor necrosis factor by its soluble receptors. J. Exp. Med. 175:323-329.

26. Sehgal, P. B., G. Grieninger, and G. Tosato, editors. 1989. Regulation of the acute phase and immune responses: interleukin 6. Ann. NY Acad. Sci. 557:583 pp.

27. Fong, Y., L. L. Moldawer, M. Marano, H. Wei, S. B. Tatter, R. H. Clarick, U. Santhanam, D. Sherris, L. T. May, P. B. Sehgal, and S. F. Lowry. 1989. Endotoxemia elicits increased circulating $\beta 2$-IFN/IL-6 in man. J. Immunol. 142:2321-2324.

28. Helfgott, D. C., S. B. Tatter, U. Santhanam, R. H. Clarick, N. Bhardwaj, L. T. May, and P. B. Sehgal. 1989. Multiple forms of IFN-B2/IL-6 in serum and body fluids during acute bacterial infection. J. Immunol. 142:948-953.

29. Jablons, D. M., J. J. Mule, J. K. McIntosh, P. B. Sehgal, L. T. May, C. M. Huang, S. A. Rosemberg, and M. T. Lotze. 1989. IL-6/IFN-B2 as a circulating hormone. Induction by cytokine administration in humans. J. Immunol. 142:1542-1547.

30. May, L. T., H. Viguet, J. S. Kenney, N. Ida, A. C. Allison, and P. B. Sehgal. 1992. High levels of "complexed" interleukin 6 in human blood. J. Biol. Chem. 267:19698-19704. 